\title{
Characteristics and antioxidant properties of cold pressed high oleic and linoleic oils from Mexican safflower varieties
}

\author{
Athziri Longoria-Sanchez', Maribel Valdez Morales², B. Dave Oomah³, Sergio Medina-Godoy', \\ Xochilt M. Ochoa-Espinoza ${ }^{4}$, Andrés M. Góngora-Gómez ${ }^{5}$, L. Gabriela Espinosa-Alonso ${ }^{1 *}$
}

${ }^{1}$ Instituto Politécnico Nacional, Centro Interdisciplinario de Investigación para el Desarrollo Integral Regional Unidad Sinaloa, Departamento de Biotecnología Agrícola, Alimentos Funcionales, Blvd Juan de Dios Bátiz Paredes 250, Col. San Joachín, Guasave, Sinaloa, México, C.P. 81101, ${ }^{2}$ CONACyT-Instituto Politécnico Nacional, Centro Interdisciplinario de Investigación para el Desarrollo Integral Regional Unidad Sinaloa, Departamento de Biotecnología Agrícola, Área de Metabolómica Agrícola, Blvd Juan de Dios Bátiz Paredes 250, Col. San Joachín, Guasave, Sinaloa, México, C.P. 81101, ${ }^{3}$ (Retired), Formerly with Summerland Research and Development Centre, Agriculture and AgriFood Canada, Summerland, British Columbia, VOH 1ZO, Canada, ${ }^{4}$ Instituto Nacional de Investigaciones Forestales, Agrícolas y Pecuarias, Oleaginous Program at Centro de Investigación Regional del Noroeste, Campo Experimental Norman E. Borlaug, Sonora, México, ${ }^{5}$ Instituto Politécnico Nacional, Centro Interdisciplinario de Investigación para el Desarrollo Integral Regional Unidad Sinaloa, Departamento de Acuacultura, Laboratorio de Malacología, Blvd Juan de Dios Bátiz Paredes 250, Col. San Joachín, Guasave, Sinaloa, México

\section{A B S T R A C T}

Six cold press oil extracted from high oleic and linoleic Mexican safflower varieties resistant/tolerant to Ramularia carthami were evaluated for their composition, physicochemical characteristics and antioxidant activity. High oleic varieties were rich in oleic (65-78\%), linoleic $(9-15 \%)$, palmitic $(2-5 \%)$ and stearic $(3-5 \%)$ acids, whereas high linoleic oils contained $76-79 \%$ linoleic, $6-9 \%$ oleic, palmitic $6-10 \%$ and $3-5 \%$ stearic acids. Calculated oxidative stability was highly associated with monounsaturated fatty acid content. High linoleate safflower oils had significantly $(p<0.05)$ higher $\mathrm{b}^{*}, \Delta \mathrm{E}$, absorbance (K232 and K272), conjugated diene, triene, peroxide and totox values, total phenolics and ORAC antioxidant activity than high oleate oils. Oil characteristics were strongly correlated with their fatty acid profile, particularly the monounsaturated/polyunsaturated ratio. Total phenolic content was moderately associated with the antioxidant activities of safflower oils ( $r=0.714$ and $0.540, p<0.001$ for DPPH and ORAC, respectively).

Keywords: Antioxidant activity; Fatty acids; Linoleic; Oleic; Physicochemical properties

\section{INTRODUCTION}

Safflower is a minor, but important oilseed crop known for its variability in fatty acid composition controlled by specific dominant genes. Five types of safflower oils have been developed; very high $(\sim 88 \%)$ and high $(71-75 \%)$ linoleic; high $(75-80 \%)$ and intermediate (41-53\%) oleic; and high (13-15\%) stearic (Rampure et al., 2015). High (80\%) linoleic acid safflower is the common commercial and leading type of safflower grown; therefore, its oil extraction, quality and characteristics have been investigated for use as cooking oil (Aydeniz et al., 2014; Bala et al., 2016; Moumen et al., 2015; Senkal et al., 2016). The intake of high linoleic safflower oil based high fat/high-sucrose diet, normally considered to be highly obesogenic, reduced weight gain and adiposity in C57BL/6J mice (Danneskiold-Samsøe et al., 2017). This diet modulated gut microbiota and liver phospholipid profiles presumably due to minor safflower oil components (carotenoids and polyphenols) (Danneskiold-Samsøe et al., 2017). In this regard, a bioavailable high linoleic safflower oil emulsion has been developed as an easily absorbed dietary supplement to increase metabolism for healthy weight management (Maru, 2014). High linoleic acid ( 78\%) safflower oil (8 $\mathrm{g}$ oil/day for 16 weeks) reduced fat mass $(6.3 \%)$ and increased total body lean mass $(1.6 \%)$ in obese postmenopausal women with type 2 diabetes (Norris et al., 2009). These dramatic physiological effects of safflower oil were associated with improvements in glycemia, inflammation

\footnotetext{
*Corresponding author:

L. Gabriela Espinosa-Alonso, Instituto Politécnico Nacional, Centro Interdisciplinario de Investigación para el Desarrollo Integral Regional Unidad Sinaloa, Departamento de Biotecnología Agrícola, Alimentos Funcionales, Blvd Juan de Dios Bátiz Paredes 250, Col. San Joachín, Guasave, Sinaloa, México, C.P. 81101. Telephone and Fax: +52(687) 8729626, Ext. 87660; E-mail: lespinosaa@ipn.mx

Received: 11 April 2019; Accepted: 22 August 2019
} 
and blood lipids due to increased (44\%) linoleic acid intake (Asp et al., 2011). However, high $(80 \%)$ oleate type has received increased interest due to its oxidative stability and low-density lipoprotein (LDL) cholesterol reduction ability (Irving et al, 1988). The chemical composition and physical properties of two commercial high oleic safflower oils have recently been reported (Salaberría et al., 2016). High oleic safflower oil is known for its nutritional benefits, its oleic acid component can improve antioxidant conditions and often used as reference oil for lipid studies and clinical trials. For example, high oleic safflower oil effectively reduced mild/ moderate HPV-induced laryngeal papillomatosis infections in children in a randomized, double blind preliminary study (Louw, 2012). High oleic safflower oil has also been incorporated in infant formula and marketed as an anticholesterol agent; it can lower low-density lipoproteins and potentially reduce arteriosclerosis (Smith, 1996).

World production of safflower was around 690,846 tones in 2017 with Mexico as the third world producer (70387 ton) (FAOSTAT, 2019). Safflower is a major alternative oilseed crop in Northwestern Mexico. An aggressive safflower breeding program begun in the early 1990's in Sonora, Mexico including both linoleic and oleic varieties, although the focus shifted primarily to oleic types by the late 1990s (Weisker and Musa, 2013). The fungal leaf disease Ramularia leaf spot (RLS) caused by Ramularia carthami that damaged the safflower crop was identified in 2000 by pathologists at CIRNO-INIFAP, a Mexican government research organization. RLS can be effectively controlled by chemical fungicides, but the treatments are costly thereby inducing the development of RLS resistant Mexican safflower variety such as S-334 (also known as ATCC accession No. PTA-10161) (Weisker and Musa, 2013). CIANO-LIN, RC-1002, RC-1005 and RC-1033 are the first linoleic commercial varieties and CIANO-OL the first oleic variety developed and released in Mexico tolerant to Ramularia carthami (Montoya-Coronado, 2008).

Two types of oils (high oleic and high linoleic acids) from safflower recently developed by the CIRNO-CENEBINIFAP were examined in an effort to increase their use for food and/or other industries. For this purpose, the objective of this work is to describe the chemical composition, including fatty acid profile, $\alpha$-tocopherol, phenolic content, quality and oxidative stability parameters and antioxidant activity of cold pressed safflower oils from Mexico.

\section{MATERIALS AND METHODS}

\section{Materials}

Safflower (Carthamus tinctorius L.) seeds were provided by INIFAP-CIRNO-CENEB in Valle del Yaqui, Sonora. The crop fertilization was pre-planting by addition of 150 units of nitrogen and 50 units of phosphorous per hectare. Two relief irrigations distributed during the spring summer 2015 cycle were administered. The seed management prior to sowing and postharvest was $17^{\circ} \mathrm{C}$. Once they were taken to the laboratory, the seeds were stored at $4{ }^{\circ} \mathrm{C}$ until oil extraction. High oleic materials were S-334, Ciano-OL and Chey-OL; and the high linoleic were RC-1002, Ciano-Lin and RC-1033. S-334, Ciano-Lin, RC-1002, RC-1033 and Ciano-OL are new safflower varieties with high tolerance to Ramularia carthami than the conventional commercial varieties CW-88OL and CW-99OL (Montoya-Coronado, 2008; Weisker and Musa 2013).

\section{Oil extraction}

The seed oil was obtained from $500 \mathrm{~g}$ of each safflower material by cold press $\left(\sim 3000 \mathrm{~kg} / \mathrm{cm}^{2}\right)$ using a Truper hydraulic jack (TRUPER S.A. de C.V., Mexico) at room temperature. Oils were stored in $100 \mathrm{~mL}$ amber bottles, oxygen purged with nitrogen, and stored at $4{ }^{\circ} \mathrm{C}$ until analysis.

\section{Analytical methods}

The fatty acid composition of the seed oils was analyzed by simultaneous extraction and methylation according to previously described method (Bannon et al., 1982), followed by gas chromatography-mass spectrometry (GC-MS). The GC-MS/MS System SCION TQ (Bruker Corporation, Billerica, Massachusetts, USA) was equipped with an autosampler (CP-8400), coupled to an electrochemical ionizer and a quadrupole detector. Helium was used as the carrier gas ( $1 \mathrm{~mL} / \mathrm{min}$, flow constant). The methyl fatty acids were identified with a standard mixture of fatty acid methyl esters (Supelco 37 Component FAME mix, Sigma Aldrich, Inc., USA) and internal standardization $(10 \mathrm{mg} / \mathrm{mL}$, methyl heptadecanoate $\mathrm{C} 17: 0$ ) was used for the quantification, and results are expressed as relative percentage of the sum of all identified methyl esters. Methyl esters of fatty acids were separated on a (5\%-Phenyl)-methylpolysiloxane (HP-5, $30 \mathrm{~m}$ x $0.53 \mathrm{~mm}$, Agilent Technologies, Waldbronn, Germany) column with the film thickness of $0.88 \mu \mathrm{m}$. Sample $(1 \mu \mathrm{L})$ was carried by splitless injection and analyzed in Full Scan, SIM program. The injector and oven temperatures were set at $250^{\circ} \mathrm{C}$ and $210^{\circ} \mathrm{C}$, respectively. The temperature of the column was set at $50^{\circ} \mathrm{C}$ for $1 \mathrm{~min}$, and increased to $230^{\circ} \mathrm{C}$, at $5{ }^{\circ} \mathrm{C} / \mathrm{min}$, and held constant for $8 \mathrm{~min}$.

The oxidizability (Cox) value of the oils was calculated by the percentage of $\mathrm{C} 18$ fatty acids applying earlier proposed formula (Fatemi and Hammond, 1980):

$$
\operatorname{Cox}=(1[\mathrm{C} 18: 1 \%]+10.3[\mathrm{C} 18: 2 \%]+21.6[\mathrm{C} 18: 3 \%]) / 100
$$

The atherogenic index (AI) and thrombogenic index (TI) were computed according to Ulbricht and Southgate 
(1991) as a ratio between some saturated and unsaturated fatty acids:

$\mathrm{AI}=\left(\mathrm{C} 12: 0+4 \times \mathrm{C} 14: 0+\mathrm{C} 16: 0 /\left[\sum \mathrm{MUFA}+\sum(\mathrm{n}-6)+\sum(\mathrm{n}-3)\right]\right)$

$\mathrm{TI}=(\mathrm{C} 14: 0+\mathrm{C} 16: 0+\mathrm{C} 18: 0) /\left[0.5 \times \sum \mathrm{MUFA}+0.5 \times\right.$ $\left.\left.\sum(\mathrm{n}-6)+3 \times \sum(\mathrm{n}-3)+\sum(\mathrm{n}-3) / \sum(\mathrm{n}-6)\right]\right)$

Oil moisture was determined following the IUPAC (1987) standard method. Official Methods (American Oil Chemists' Society, AOCS 2008) were used to determine acid, peroxide (PV) and $p$-anisidine ( $p$-AV) values of oils (methods Cd 3d-63, Cd 8-53 and Cd 18-90, respectively). Total oxidation index (Totox) was calculated based on the $\mathrm{PV}$ and $p$-AV values of oils where Totox $=2 \mathrm{X} \mathrm{PV}+p-\mathrm{AV}$. CIELAB color coordinate ( $\mathrm{L}^{*}, \mathrm{a}^{*}$, and $\left.\mathrm{b}^{*}\right)$ of oils were measured with a Minolta colorimeter (CR-400, Konica Minolta Sensing Inc., Japan), using a white plate $\left(\mathrm{L}^{*}=94.81\right.$, $a^{*}=0.00, b^{*}=2.31$ and $\left.D^{*}=43.55\right)$ as reference for color difference (DE). Absorbance was recorded at 232 and $270 \mathrm{~nm}$ (UV-visible Multiskan ${ }^{\text {TM }}$ GO spectrophotometer, Thermo Fisher Scientific Inc., MA, USA) using hexane as blank for the measurement of conjugated dienes and trienes. Oil was diluted with hexane $(10 \% \mathrm{v} / \mathrm{v})$.

The polar compounds were extracted from oils with absolute methanol $(1: 2.5 \mathrm{v} / \mathrm{v})$ as described previously (Lavelli, 2002) and the total phenolic content was determined spectrophotometrically (Nurmi et al., 1996) using the Folin-Ciocalteau reagent (Sigma Chemical Co., St. Louis, MO, USA). The blue complex formed after the addition of $\mathrm{Na}_{2} \mathrm{CO}_{3}(40 \mu \mathrm{L}, 7.5 \%)$ to the mixture of Folin-Ciocalteu reagent $(10 \mu \mathrm{L}, 1 \mathrm{~N})$ and the oil extract $(10 \mu \mathrm{L})$ was measured at $760 \mathrm{~nm}\left(\mathrm{UV}-\right.$ visible Multiskan ${ }^{\mathrm{TM}}$ GO spectrophotometer, Thermo Fisher Scientific Inc., MA, USA) after incubation $\left(15 \mathrm{~min}, 45^{\circ} \mathrm{C}\right)$. Gallic acid (20- $200 \mu \mathrm{g} / \mathrm{mL}$ ) was used as standard.

The $\alpha$-tocopherol was extracted according to previous report (Cerretani et al., 2009) and the content was measured using high-performance liquid chromatography with a diode array detector (HPLC-DAD) (DIONEX Ultimate 3000, Thermo Fisher Scientific Inc., MA, USA). A Discovery (HS-C18, $3 \mu \mathrm{m}, 15 \mathrm{~cm} \times 2.1 \mathrm{~mm}$, SigmaAldrich Inc., Steinheim, Germany) column was used with formic acid $0.015 \%$, acetonitrile and methanol as mobile phase at $0.25 \mathrm{~mL} / \mathrm{min}$ flow rate and $10 \mu \mathrm{L}$ injection volume. An ultraviolet DAD detector was used to identify $\alpha$-tocopherol at $292 \mathrm{~nm}$. The $\alpha$-tocopherol was quantified by standardization with $\mathrm{dl}-\alpha$-tocopherol $(0.05-1 \mathrm{mg} / \mathrm{mL})$.

The DPPH assay was performed as previously reported (Fukumoto and Mazza, 2000), with some modifications (Cardador-Martinez et al., 2006). A solution $(0.24 \mu \mathrm{M})$ of the radical DPPH (2,2-diphenyl-1-picrylhydrazyl radical) was added to $20 \mu \mathrm{L}$ of sample. The kinetic was monitored every $10 \mathrm{~min}$ for $90 \mathrm{~min}$ at $515 \mathrm{~nm}$ (UV-visible Multiskan ${ }^{\mathrm{TM}} \mathrm{GO}$ spectrophotometer, Thermo Fisher Scientific Inc., MA, USA). Trolox $(50-500 \mu \mathrm{M})$ was used as standard for the calibration curve. The ORAC assay was performed as described previously (Oomah et al., 2008) based on the established procedure (Prior et al., 2003). A Multimode detector (DTX 880, Beckman Coulter, Perkin Elmer Inc., MA, USA) was used with excitation and emission wavelengths at 485 and $530 \mathrm{~nm}$, respectively. Methanol extracts of the oils and Trolox standards were diluted $(1: 5 \mathrm{v} / \mathrm{v})$ with $75 \mathrm{mM}$ phosphate buffer ( $\mathrm{pH}$ 7.4) prior to transfer to a 96-well microplate (Costar Black assay plate 3615, MA, USA). A peroxyl radical was generated by 2,2'-azobis (2-methyl-propionamide) dichloride (AAPH; Sigma Aldrich Inc., USA) during measurement, and fluorescein was used as the substrate. The measurements were taken every 2 min for 150 min upon AAPH addition.

\section{Statistical analysis}

All determinations were conducted in three independent experiments. The data were analyzed by one-way analysis of variance (ANOVA) followed by Tukey's range test using Statgraphics Centurion XV software (Manugistics Inc., USA). Values with $p<0.05$ were considered significantly different among the samples.

\section{RESULTS AND DISCUSSION}

Oil yield was generally higher for high linoleic than high oleic safflower varieties, except for RC-1033 with the lowest yield $(10.5 \%$, probably due to poor filled seed). The average oil yields for linoleic and oleic varieties $(20.49 \pm 0.16$ and $17.65 \pm 0.44 \%$, respectively) were within values reported earlier for a registered high linoleic Turkish safflower variety Dinçer harvested in 2011 (Aydeniz et al, 2014).

Our previous preliminary analysis of Ciano-OL, S-334 and RC-1033 safflower harvested in 2013 showed a drastic reduction $(\sim 50 \%)$ in cold pressed oil yield compared to Soxhlet solvent extraction $(34.9 \pm 2.1,37.3 \pm 0.71$ and $37.5 \pm 2.8 \%$, respectively). This is in accordance with the reduction $(\sim 40 \%)$ reported for Dinçer that contained $27.8 \%$ oil determined by Soxhlet extraction (Aydeniz et al., 2014). Oil content (Soxhlet hexane extraction) of Ciano-Lin, RC-1002 and RC-1033 grown in Sonora was 41.5, 40.5 and 40.8\% (Montoya-Coronado, 2008), about $3 \%$ higher than those genotypes grown in India (Kadirvel et al., 2016). Ciano-OL, the only high oleic safflower variety medium tolerant to Ramularia carthami was reported to have the lowest oil content (37.4\%) (Montoya-Coronado, 2008). Oil content depends on hull types, environmental factors (location) and may vary from 20-47\% (Ahmadzadeh 
et al., 2014). The high oleic safflower seed oil content ranged between 42 and $46 \%$ obtained using conventional extraction and refining methods (Salaberría et al., 2016).

Major fatty acids were $65-78 \%$ oleic, $9-15 \%$ linoleic, $2-5 \%$ palmitic and stearic 3-5\% for the high oleic varieties, whereas high linoleic oils contained $76-79 \%$ linoleic, 6-9\% oleic, palmitic $6-10 \%$ and $3-5 \%$ stearic acids (Table 1). The high oleic variety Chey-OL displayed intermediate palmitic (5.7\%) and oleic (65.8\%), and low linoleic $(9.4 \%)$ and stearic $(3.0 \%)$ acids. S-334, Ciano-OL, and RC-1002 oils had medium $(\sim 5 \%)$ stearic acid content. Total linoleate + oleate did not change appreciably except for S-334 (91.5\%) and Chey-OL $(75 \%)$ indicating a shift in their fatty acid. This shift resulted in the lowest and highest saturated fatty acid content of S-334 and Chey-OL oil, respectively, compared to other varieties. Higher palmitic and oleic acids and lower stearic and linoleic acids have been reported for oils from Ciano-OL, Ciano-Lin, RC-1002 and RC-1033 grown in India (Kadirvel et al., 2016). Thus, the linoleic/oleic ratio of oils from these varieties (Ciano-OL, RC-1002, RC-1033 and Ciano-Lin) was higher $(0.53,2.43,1.23$ and $1.81 \mathrm{x}$, respectively) than those reported recently (Kadirvel et al., 2016). The oleic acid content of Ciano-Lin oil was lower $(\sim 24 \%)$ than previous report (Borbón-Gracia et al., 2011). Oils from high oleic varieties were on average more resistant $(5.3 \times)$ to oxidation relative to those from high linoleate varieties based on the calculated oxidizability (Cox) value. Oxidative stability (Cox) was highly inversely correlated $(Y=-0.2022$ MUFA + 18.619; $\left.r^{2}=-0.989\right)$ with monounsaturated fatty acid levels. The Cox values of high oleic safflower oils were similar to those of canola and olive oil (Farahmandfar et al., 2015; Farhoosh et al., 2009). The polyunsaturated/saturated ratio of high linoleic oils was considerably $(\sim 5 \times)$ higher than those of high oleic oils. Atherogenic and thrombogenic indices were similar to those reported for sunflower and olive oils $(0.07$ and 0.14 for atherogenic; and 0.28 and 0.32 for thrombogenic index, respectively) (Ulbricht and Southgate, 1991). All safflower oils displayed low atherogenic and thrombogenic indices (Table 1) and may therefore be potentially favorable for reduction of serum cholesterol and atherosclerosis and heart disease prevention (Rudel et al., 1995). Consumption of these oils should be encouraged in the context of their low atherogenic and thrombogenic indices.

Table 1: Fatty acid contents, atherogenic and thrombogenic indices of high oleic and linoleic safflower oils ${ }^{a}$

\begin{tabular}{|c|c|c|c|c|c|c|c|c|}
\hline \multirow{2}{*}{\multicolumn{2}{|c|}{ Fatty acid ${ }^{b}$}} & \multirow[t]{2}{*}{ CAS } & \multicolumn{3}{|c|}{ High oleic } & \multicolumn{3}{|c|}{ High linoleic } \\
\hline & & & S-334 & Ciano-OL & Chey-OL & RC-1002 & Ciano-Lin & RC-1033 \\
\hline \multicolumn{9}{|c|}{ Saturated fatty acid (SFA) } \\
\hline Myristic acid & C14 & $124-10-7$ & 0.343 & 1.779 & 2.212 & 0.837 & 0.179 & 0.269 \\
\hline Pentadecanoic acid & C15 & $7132-64-1$ & 0.044 & 0.271 & 2.178 & 0.428 & 0.024 & 0.038 \\
\hline Palmitic acid & C16 & $112-39-0$ & 2.379 & 3.002 & 5.741 & 6.289 & 8.005 & 10.098 \\
\hline Stearic acid & C18 & $112-61-8$ & 5.492 & 5.160 & 3.007 & 5.893 & 3.788 & 3.514 \\
\hline Arachidic acid & $\mathrm{C} 20$ & $1120-28-1$ & nd & 0.171 & 3.449 & 0.400 & nd & 0.005 \\
\hline Others $^{1}$ & & & nd & nd & 0.756 & nd & nd & nd \\
\hline \multicolumn{9}{|c|}{ Monounsaturated fatty acid (MUFA) } \\
\hline Myristoleic acid & C14:1 & $56219-06-8$ & 0.011 & 0.012 & 0.062 & 0.053 & 0.016 & 0.014 \\
\hline Palmitoleic acid & $\mathrm{C} 16: 1$ & $1120-25-8$ & 0.100 & 0.384 & 2.175 & 0.585 & 0.025 & 0.058 \\
\hline Oleic acid & C18:1 & $112-62-9$ & 76.246 & 78.461 & 65.809 & 6.792 & 8.679 & 9.677 \\
\hline Others $^{2}$ & & & 0.026 & 0.217 & 2.998 & 0.190 & 0.003 & 0.008 \\
\hline \multicolumn{9}{|c|}{ Polyunsaturated fatty acid (PUFA) } \\
\hline Linolenic acid & $\mathrm{C} 18: 2 \Omega 3$ & $301-00-8$ & 0.022 & 0.070 & 1.073 & 0.302 & 0.023 & 0.023 \\
\hline Linoleic acid & $\mathrm{C} 18: 2 \Omega 6$ & $2566-97-4$ & 15.312 & 10.394 & 9.456 & 77.951 & 79.234 & 76.252 \\
\hline Others $^{3}$ & & & 0.001 & 0.001 & 0.035 & 0.082 & 0.002 & 0.012 \\
\hline Oleic+linoleic & & & 91.56 & 88.86 & 75.26 & 84.74 & 87.91 & 85.92 \\
\hline Linoleic/oleic & & & 0.20 & 0.13 & 0.14 & 11.48 & 9.13 & 7.88 \\
\hline$\Sigma$ SFA & & & 8.26 & 10.38 & 17.34 & 13.85 & 12.00 & 13.92 \\
\hline$\Sigma$ MUFA & & & 76.38 & 79.07 & 71.04 & 7.62 & 8.72 & 9.76 \\
\hline$\Sigma$ PUFA & & & 15.34 & 10.47 & 10.56 & 78.33 & 79.26 & 76.29 \\
\hline PUFA/SFA & & & 1.86 & 1.0 & 0.61 & 5.7 & 6.6 & 5.5 \\
\hline MUFA/PUFA & & & 4.98 & 7.55 & 6.73 & 0.1 & 0.11 & 0.13 \\
\hline Oxidizability value & & & 2.34 & 1.86 & 1.74 & 8.13 & 8.25 & 7.95 \\
\hline Atherogenic index & & & 0.04 & 0.11 & 0.18 & 0.11 & 0.10 & 0.13 \\
\hline Thrombogenic index & & & 0.18 & 0.22 & 0.25 & 0.30 & 0.27 & 0.32 \\
\hline
\end{tabular}

${ }^{a}$ Expressed as mg/kg oil, SFA, saturated; MUFA, monounsaturated; PUFA polyunsaturated; PUFA/SFA, polyunsaturated/saturated ratio, fatty acids, respectively. Cox, oxidizability value, Al, atherogenic index; TI, thrombogenic index; nd, no detected below 0.001, ${ }^{1}$ mix of SFA: Heneicosanic acid (C21, CAS 6064-90-0); Behenic acid (C22, CAS 929-77-1); Tricosanoic acidC23, CAS 2433-97-8; Lignoceric acid (C24, CAS 2442-49-1), ${ }^{2}$ mix of MUFA: cis-10-Heptadecenoic acid (C17:1 CAS 75190-82-8); cis-11-Eicosenoic acid (C20:1 CAS 2390-09-2; erucic acid (C22:1, CAS 1120-34-9); Nervonic Acid (C24:1, CAS 2733-88-2), ${ }^{3} \mathrm{mix}$ of PUFA: Eicosatrienoic acid (C20:3 $\Omega 3$, CAS 55682-88-7); 5,8,11,14,17-Eicosapentaenoic acid (C20:5 $\Omega 3$, CAS 2734-47-6). 
Moisture content varied significantly with oils from Ciano-OL and Ciano-Lin displaying the highest value, one order of magnitude than from other safflower varieties (Table 2). Furthermore, moisture content of oil from these two varieties exceeded the limit $(\leq 0.2 \%)$ for cold pressed and virgin oils according to the Codex Alimentarius Commission standard (1999). The values obtained for the other varieties $(0.02-0.06 \%)$ were lower than those reported for fresh sunflower oils (0.1\%) (Sadoudi et al., 2014). The lowest moisture content of RC-1002 oil was twice the value for safflower oil ( $87 \pm 5.2 \mathrm{ppm})$, and almost one-fifth of extra olive oil $(850 \pm 12.3 \mathrm{ppm})$ determined by FTIR (Al-Alawi et al., 2006).

High linoleate safflower oils had significantly $(p<0.05)$ higher $\mathrm{b}^{*}$ and $\Delta \mathrm{E}$ and lower $\mathrm{a}^{*}$ values than high oleate varieties indicating a marked trend toward green and yellow, probably due to higher pigment (carotenoid and chlorophyll) content. The lightness ( $\left.\mathrm{L}^{*} \sim 31\right)$ did not differ significantly among oils and was similar to those of cold pressed Turkish safflower variety Dinçer (34.05), but with different $\mathrm{a}^{*}$ and $\mathrm{b}^{*}$ values (1.33 and 30.08 , respectively) (Aydeniz et al., 2014). The negative a* (-1.7 to -2.2$)$ within the range of virgin olive oils (-0.6 to -3.8) (Moyano et al., 2008) and low b* (5.9-8.4) values indicate bright yellow-green color of the oils. Hexane extracted oil from high oleic cultivars CW88-OL and CW99-OL (Salaberría et al., 2016) also displayed negative $\mathrm{a}^{*}$ values (-3.7 and -3.1, respectively), although their $\mathrm{L}^{*}(\sim 89)$ and $\mathrm{b}^{*}(\sim 47)$ values were higher than those observed in our study.

High oleate safflower oils displayed significantly $(p<0.05)$ lower absorbance values measured in the UV region $(232$ and $270 \mathrm{~nm}$ ) than those from high linoleate varieties (Table 2). K232 and K270 indicators of primary and secondary oxidation products, respectively of high linoleate oils were 9 and 3 folds those from high oleate varieties. Our K232 and K270 values of high linoleate oils were higher and lower, respectively than those reported for hexane extracted oils from high linoleate Turkish safflower varieties (Senkal et al., 2016). High absorptivity at $230 \mathrm{~nm}$ of high linoleate oils may be due to high diene conjugation confirmed by their high diene value ( $\sim 10$ folds the values for high oleate oils). The greater amount of linoleic acid and the higher amount of unsaturated fatty acids in the high linoleate oils exert potential rise in conjugated diene formation. Conjugated diene and triene values of high linoleate oils paralleled the same trends observed with absorptivity at 230 and $270 \mathrm{~nm}$; (i.e. $\sim 10$ and 2.7 times, respectively the values of high oleate oils). Diene values of high linoleate oils were similar to those of commercial safflower oil (Oomah et al., 2000) and commercial cold pressed safflower oil (Prescha et al., 2014), whereas triene values were minimal $(2.5 \%)$. The low conjugated triene values suggest absence or very low levels of linolenate oxidation, particularly for the high oleate safflower oils.

The lipid hydroxide content defined by the peroxide value was significantly higher in high linoleate ( $\sim$ folds) than in high oleate oils (Table 2). Peroxide value did not differ significantly among high oleate oils and was within the range reported for cold pressed safflower oils (Aydeniz et al., 2014; Prescha et al., 2014) or commercial safflower oils (Ahmadzadeh et al., 2014; Oomah et al., 2000). The peroxide values of high linoleate oils were similar to those reported for hexane extracted oils from two high linoleate safflower varieties (Cartafri and Sharda) grown in Morocco (Moumen et al., 2015). The peroxide values of all safflower oils were lower than the maximum limit $\left(20\right.$ meq $\mathrm{O}_{2} / \mathrm{kg}$ ) established for extra virgin olive oils, whereas those of high oleate oils were below the limit of international standards (10 meq $\mathrm{O}_{2} / \mathrm{kg}$ ) for safflower oil.

Table 2: Physicochemical and oxidatative characteristics of high oleic and linoleic safflower oils ${ }^{a}$

\begin{tabular}{|c|c|c|c|c|c|c|c|c|}
\hline \multirow[t]{2}{*}{ Characteristic } & \multicolumn{3}{|c|}{ High oleic } & \multicolumn{3}{|c|}{ High linoleic } & \multicolumn{2}{|c|}{ Mean } \\
\hline & S-334 & Ciano-OL & Chey-OL & RC-1002 & Ciano-Lin & RC-1033 & Oleic & Linoleic \\
\hline Moisture $(\mathrm{g} / 100 \mathrm{~g})$ & $0.038 \mathrm{c}$ & $0.313 a$ & $0.060 \mathrm{~b}$ & $0.017 d$ & $0.327 a$ & $0.053 b c$ & $0.14 x$ & $0.13 x$ \\
\hline $\mathrm{L}^{*}$ & 30.89 & 30.91 & 30.95 & 30.80 & 30.86 & 30.84 & $30.92 x$ & $30.83 x$ \\
\hline$a^{*}$ & $-1.98 d$ & $-1.70 b$ & $-1.67 a$ & $-1.93 c$ & $-1.98 d$ & $-2.18 e$ & $-1.78 x$ & $-2.03 y$ \\
\hline$b^{*}$ & $6.94 d$ & $5.91 e$ & $5.91 \mathrm{e}$ & $7.35 b$ & $7.16 \mathrm{c}$ & $8.41 \mathrm{a}$ & $6.25 y$ & $7.64 x$ \\
\hline$\Delta \mathrm{E}$ & $58.40 \mathrm{c}$ & $58.12 d$ & $58.08 d$ & $58.61 b$ & $58.49 \mathrm{c}$ & $58.94 a$ & $58.20 y$ & $58.68 x$ \\
\hline $\mathrm{K}_{232}$ & $0.065 d$ & $0.053 d$ & $0.061 d$ & $0.47 c$ & $0.71 \mathrm{a}$ & $0.16 b$ & $0.06 y$ & $0.58 \mathrm{x}$ \\
\hline $\mathrm{K}_{268}$ & $0.005 d$ & $0.001 d$ & $0.015 c$ & $0.022 \mathrm{bc}$ & $0.039 a$ & $0.024 b$ & $0.006 y$ & $0.028 x$ \\
\hline $\mathrm{K}_{278}$ & $0.006 d$ & $0.003 d$ & $0.014 c$ & $0.022 \mathrm{bc}$ & $0.038 a$ & $0.024 b$ & $0.007 y$ & $0.028 x$ \\
\hline Diene value & $0.051 d$ & $0.038 d$ & $0.054 d$ & $0.401 c$ & $0.628 a$ & $0.482 b$ & $0.048 y$ & $0.504 x$ \\
\hline Triene* 1000 & $1.62 \mathrm{c}$ & $1.15 c$ & $0.92 c$ & $2.80 \mathrm{~b}$ & $4.33 a$ & $2.75 b$ & $1.23 y$ & $3.29 x$ \\
\hline Acid value $^{b}$ & $0.52 b$ & $0.52 b$ & $0.41 b$ & $0.41 b$ & $0.75 a$ & $0.45 b$ & $0.48 x$ & $0.53 x$ \\
\hline Peroxide value $^{c}$ & $3.87 \mathrm{c}$ & $3.98 c$ & $3.92 \mathrm{c}$ & $17.24 a$ & $16.36 a$ & $13.20 \mathrm{~b}$ & $3.92 y$ & $15.60 x$ \\
\hline$p$-Anisidine value ${ }^{c}$ & $0.72 \mathrm{c}$ & $0.73 c$ & $0.56 c$ & $1.84 \mathrm{a}$ & $0.53 \mathrm{c}$ & $1.22 \mathrm{~b}$ & $0.67 y$ & $1.20 x$ \\
\hline TOTOX & $8.46 d$ & $8.69 d$ & $8.34 d$ & $36.33 a$ & $33.24 b$ & $27.61 \mathrm{c}$ & $8.51 y$ & $32.39 x$ \\
\hline
\end{tabular}

${ }^{a}$ Means in a row with different letters are significantly different $(p<0.05),{ }^{b}$ Acid values are expressed in $\mathrm{mg} \mathrm{KOH} / \mathrm{g}$ oil, ${ }^{c} \mathrm{Peroxide}$ and $p$-anisidine values are expressed in $\mathrm{mmol} \mathrm{H}_{2} \mathrm{O}_{2} / \mathrm{kg}$ oil. 
Only oils from RC-1002 and RC-1033 had significantly higher $p$-anisidine values $(\geq 2 \mathrm{x})$ reflecting the content of secondary lipid oxidation products than oils from other varieties. The $p$-anisidine values of our oils were lower than those reported for commercial safflower and industrially cold press safflower oils (Oomah et al., 2000; Prescha et al., 2014). Totox value of high linoleate oils was significantly higher $(\sim 4 \mathrm{x})$ than high oleate oils, similar to those observed with primary oxidation (PV), suggesting minimal or negligible effects of secondary oxidation on the total overall oil oxidation status. The high totox of high linoleate oils confirms their greater susceptibility to oxidation according to their oxidizability index (Table 1). High oleate oils displayed totox values lower than commercial safflower oil (12.4) (Oomah et al., 2000) and similar $(\sim 7)$ to some vegetable oils (Shukla and Perkins, 1998). Acid value (AV) was not significantly different among safflower oils except for Ciano-Lin (with the highest value). The AV were within the range for commercial safflower oil (Ahmadzadeh et al., 2014), but higher than those reported for cold pressed commercial safflower oils (Prescha et al., 2014) and within the limit ( $\leq 4 \mathrm{mg} \mathrm{KOH/g}$ oil) according to the Codex Alimentarius standard (1999) for cold pressed and virgin oils.

Total phenolic content of high linoleate oils was significantly higher $(\sim 60 \%)$ than those from high oleate safflower varieties. Oils from RC-1033 and Ciano-Lin displayed the highest and lowest total phenolic acid contents, respectively (Table 3). Phenolic content of our oils was higher ( $7-11$ fold $)$ than those of cold pressed Turkish safflower oil (Aydeniz et al., 2014) and hexane extracted safflower oil (Moumen et al., 2015). Total phenolic content of safflower oils was higher than most vegetable oils, particularly one order of magnitude those of commercially refined corn or extra virgin olive oils (30.8 and $15.2 \mathrm{mg}$ gallic acid equivalent/kg oil, respectively) (Farhoosh et al., 2009). Alpha-tocopherol content of oils from two oleate varieties (Ciano-OL and Chey-OL) did not differ significantly from linoleate varieties (RC-1033 and RC-1002). The $\alpha$-tocopherol content of our safflower oils was lower than those reported for cold pressed (rapeseed, sunflower and safflower oil) (Franke et al., 2010; Lee et al., 2004), hexane extracted oil (Salaberría et al., 2016), commercial safflower oils (Oomah et al., 2000; Bozan and
Temelli, 2008), and the Codex standard for $\alpha$-tocopherol in crude safflower oil (234-660 mg/kg oil) (Table 3). The relatively higher total phenolic and lower $\alpha$-tocopherol contents of our safflower oils may partly be due to the use of absolute methanol that is superior to aqueous methanol $(80 \%)$ for phenolic extraction from oils but hinders precise quantification of $\alpha$-tocopherol (Owen et al., 2000).

Oil from the high oleate and high linoleate sunflower cultivars S-334 and Ciano-Lin exhibited the lowest and highest DPPH antioxidant activity, respectively (Table 3). S-334, Chey-OL and RC-1033 oils did not differ significantly in DPPH radical scavenging activity. The DPPH values were lower than cold pressed Turkish safflower oil (Aydeniz et al., 2014), and cold pressed commercial safflower oils (Prescha et al., 2014). ORAC unlike DPPH values differed significantly among safflower varieties with oils from high linoleate displaying higher radical scavenging activity than high oleate varieties. The ORAC values have rarely been reported for safflower oils but are within the range for virgin olive oils (1-10 $\mu \mathrm{M}$ trolox/g oil) (Ninfali et al., 2002; Samaniego-Sánchez et al., 2007) (Table 3). Total phenolic content was associated with the antioxidant activities of safflower oils $(r=0.714 ; p<0.001$ and $r=0.540$; $p=0.0007$ for DPPH and ORAC, respectively). However, $\alpha$-tocopherol content did not correlate with the antioxidant activities of the oils although safflower was reported to exhibit the highest DPPH radical scavenging activity for its lipophilic fraction (Zhang et al, 1997). This may be due to the presence of some serotonin derivatives found in safflower oil cake that exerts stronger antioxidant activities than $\alpha$-tocopherols (Zhang et al., 1997).

Oil characteristics were strongly correlated with their fatty acid profile, particularly the monounsaturated/ polyunsaturated ratio (Table 2). This ratio is often considered a measure of oil tendency to oxidation; the higher the ratio the greater the oxidative stability of the oil in the frying process (Farahmandfar et al., 2015). It was highly inversely associated with the peroxide, totox and $\triangle \mathrm{E}$ values, total phenolics and DPPH radical scavenging activity $(r=-0.70$ to $-0.96 ; p<0.0001)$ and moderately correlated with $\mathrm{p}$-anisidine and ORAC values $(r=-0.53$ to $-0.52, p<0.001)$. The color indicator $\mathrm{b}^{*}$ and absorptivity K232 were highly correlated with total

Table 3: Total phenolics, $\alpha$-tocopherol and antioxidant activity of high oleic and linoleic safflower oils ${ }^{a}$

\begin{tabular}{|c|c|c|c|c|c|c|c|c|}
\hline \multirow[t]{2}{*}{ Characteristic } & \multicolumn{3}{|c|}{ High oleic } & \multicolumn{3}{|c|}{ High linoleic } & \multicolumn{2}{|c|}{ Mean } \\
\hline & S-334 & Ciano-OL & Chey-OL & RC-1002 & Ciano-Lin & RC-1033 & Oleic & Linoleic \\
\hline Total phenolics ${ }^{b}$ & $19.27 \mathrm{c}$ & $17.05 d$ & $18.04 \mathrm{~cd}$ & $29.26 a b$ & $28.60 \mathrm{~b}$ & $30.39 a$ & $18.12 y$ & $29.41 x$ \\
\hline$\alpha$-Tocopherol ${ }^{c}$ & $148.92 d$ & 213.61a & $166.53 c$ & $173.95 c$ & $195.42 b$ & $214.26 a$ & $176.35 y$ & $194.54 x$ \\
\hline $\mathrm{DPPH}^{d}$ & $51.48 b$ & $47.57 \mathrm{~b}$ & $75.51 a$ & $68.87 a$ & $79.58 a$ & $72.57 a$ & $58.19 y$ & $73.67 x$ \\
\hline ORAC $^{d}$ & $1.74 b$ & $1.40 \mathrm{c}$ & $1.16 \mathrm{~d}$ & $1.88 b$ & $2.57 a$ & $1.52 \mathrm{c}$ & $1.43 y$ & $1.99 x$ \\
\hline
\end{tabular}

${ }^{a}$ Means in a row with different letters are significantly different $(p<0.05),{ }^{b}$ Total phenols are expressed as $\mathrm{mg}$ equivalents gallic acid/100 $\mathrm{g}$ oil, ${ }^{c} \alpha$-Tocopherol are expressed as mg/kg oil, ${ }^{d}$ Antioxidant activity expressed as $\mathrm{mg}$ Trolox equivalents $/ \mathrm{kg}$ oil. 
phenolic content and DPPH antiradical scavenging activity. The diene and triene values were inversely correlated with the monounsaturated/polyunsaturated fatty acid ratio but positively associated with peroxide, totox, total phenolic and DPPH values. $p$-anisidine values were only moderately correlated explaining its relatively low contribution to the variability of other oil characteristics. The correlation coefficients suggest that the oleate/linoleate content of the oil (expressed here as the monounsaturated/ polyunsaturated fatty acid ratio) strongly affects its physical characteristics, phenolic content and the DPPH radical scavenging activity.

Most dietary recommendations often advise the reduction of saturated fat intake and maintain or increase PUFA intake. Total fat, SFA, MUFA and PUFA intake for adults (19-69 years) in Mexico was 25.7, 7.4, 7.2 and 4.4\% of total energy. The PUFA intake, important for preventing chronic diseases, was lower than the WHO/FAO recommended population nutrient intake (6-8\% energy) (Elmadfa and Kornsteiner, 2009). High consumption of SFA and MUFA has been associated with increased risk, whereas PUFA intake reduced $(70-80 \%)$ that risk of gastric cancer in Mexico (López-Carrillo et al., 1999; Sampieri and Mora, 2014). The main sources of PUFA in the Mexican diet are sunflower and safflower oils; therefore increased use of our high linoleic safflower oil (75-86\% PUFA, 10-23 PUFA/SFA ratio) can be effective in greatly reducing the risk of gastric cancer, the third leading cause of cancer related deaths in Mexico (Bustos-Carpinteyro et al., 2016). Furthermore, the antioxidant components of safflower oil, particularly the phenolics may also play an important etiological role in reducing the risk of chronic diseases and attenuating inflammation, the major risk factor for metabolic diseases.

\section{CONCLUSION}

Mexican safflower oils exhibited distinctive physicochemical characteristics from high oleic and linoleic, strongly correlated with their fatty acid profile, particularly the monounsaturated/polyunsaturated ratio. Oleic oil yield was $\sim 14 \%$ lower than linoleic safflower varieties. The cold press extraction method reduces oil yield up to $50 \%$. Major fatty acids in oils were: oleic $(65-78 \%)<$ linoleic $(9-15 \%)$, $<$ stearic $(3-5 \%)<$ palmitic $(2-5 \%)<$ myristic $(0.3-2.2 \%)$ acids for the high oleic varieties; linoleic $(76-79 \%)<$ oleic $(6-9 \%)<$ palmitic $(6-10 \%)<$ stearic $(3-5 \%)<$ myristic (0.18-0.84\%) acids for high linoleic oils. Linoleic/oleic ratio for oleic and linoleic varieties was 0.15 and 9.5 , respectively. Meanwhile, the PUFA/SFA ratio for high linoleic was $5 \mathrm{x}$ higher than high oleic oils. Based on the calculated oxidizability stability (Cox), high oleic varieties were $4 \mathrm{x}$ more resistant to oxidation than those from high linoleic, due the monounsaturated fatty acid levels. Furthermore, the measured oxidative quality parameters confirm the greater susceptibility to oxidation of linoleic oils; however, both cold press oleic and linoleic safflower oils exhibited low atherogenic and thrombogenic indices.

Total phenolic content of high linoleate oils was significantly higher $(\sim 60 \%)$ than those from high oleate safflower varieties; monounsaturated/polyunsaturated fatty acid ratio strongly affects its phenolic content and the DPPH radical scavenging activity.

High oleic and high linoleic cold press oils from improved Mexican safflower varieties could be excellent opportunity to increase the PUFA/SFA ratio consumption. Furthermore, their low atherogenic and thrombogenic indices may be potentially favorable for reduction of serum cholesterol and atherosclerosis and heart disease prevention. Besides, high oxidative stability of the oleic cold press oils and phenolic content and antioxidant activity of linoleic varieties can potentially increase their use for food and nonfood industries. More investigation on in vivo bioactivity will be necessary to complement this characterization of Mexican safflower oil for increased use in food and nonfood industries.

\section{ACKNOWLEDGMENTS}

The first author is grateful to CONACyT (CVU/ becario636046/290915) and BEIFI-IPN scholarships, Instituto Politécnico Nacional Secretaría de Investigación y Posgrado. SIP20161751 Project for providing research funds and to Oleaginous Program at Instituto Nacional de Investigaciones Forestales, Agrícolas y Pecuarias (INIFAP), Centro de Investigación Regional del Noroeste (CIRNO), Campo Experimental Norman E. Borlaug (CENEB), Sonora, Mexico, for providing safflower seeds.

The authors declare no conflicts of interest.

\section{Authors' Contributions}

A. L-S., M. V-M. and S. M-G. designed and performed the experiments, X. M. O-E. provided the experimental material, A. M. G-G. co-analyzed data. B. D. O. and L. G. E-A. analyzed the data and co-wrote the paper and supervised the research.

\section{REFERENCES}

Ahmadzadeh, S., M. Kadivar and G. Saeidi. 2014. Investigation of oil properties and seed composition in some safflower lines and cultivars. J. Food Biochem. 38: 527-532.

Al-Alawi, A., F. R. Van De Voort, J. Sedman and A. Ghetler. 2006. 
Automated FTIR analysis of free fatty acids or moisture in edible oils. JALA. 11(1): 23-29.

American Oil Chemists' Society. 2008. Official Methods and Recommended Practices of the AOCS. $6^{\text {th }}$ ed. AOCS Press, Champaign, IL.

Asp, M. L., A. L. Collene, L. E. Norris, R. M. Cole, M. B. Stout, S. Y. Tang, J. C. Hsu and M. A. Belury. 2011. Time-dependent effects of safflower oil to improve glycemia, inflammation and blood lipids in obese, post-menopausal women with Type 2 diabetes: A randomized, double-masked, crossover study. Clin. Nutr. 30(4): 443-449.

Aydeniz, B., O. Ügneşer and E. Yilmaz. 2014. Physic-chemical, sensory and aromatic properties of cold press produced safflower oil. J. Am. Oil Chem. Soc. 91: 99-110.

Bala, M., B. Madhu, S. K. Tyagi and R. K. Gupta. 2016. Optimization of supercritical $\mathrm{CO}_{2}$ extraction of safflower seed oil using response surface methodology. Asian J. Chem. 28(7): 1579-1583.

Bannon, C. D., J. D Craske, N. T Hai, N. L. Harper and K. L O'Rourke. 1982. Analysis of fatty acid methyl esters with high accuracy and reliability methylation of fats and oils with boron trifluoride methanol. J. Chromatogr. 247(1): 63-69.

Borbón-Gracia, A., X. M. Ochoa-Espinoza, L. Montoya-Coronado, J. P. Márquez and M. G. G. Camarena. 2011. CIANO-LIN: A new cultivar of linoleic safflower. Rev. Mex. Cienc. Agríc. 2(5): 791-794.

Bozan, B. and F. Temelli. 2008. Chemical composition and oxidative stability of flax, safflower and poppy seed and seed oils. Bioresour. Tech. 99(14): 6354-6359.

Bustos-Carpinteyro, A. R., N. Delgado-Figueroa, E. Santiago-Luna, M. T. Magaña-Torres and J. Y. Sánchez-López. 2016. Association between the $\mathrm{CDH} 1-472 \mathrm{del}$ A and $-160 \mathrm{C}>\mathrm{A}$ polymorphisms and diffuse and intestinal gastric cancer in a Mexican population. Genet. Mol. Res. 15(3): gmr.15038715.

Cardador-Martínez, A., A. Albores, M. Bah, V. Calderón-Salinas, E. Castaño-Tostado, R. Guevara-González, A. ShimadaMiyasaka and G. Loarca-Piña. 2006. Relationship among antimutagenic, antioxidant and enzymatic activities of methanolic extract from common beans (Phaseolus vulgaris L.). Plant Food Hum. Nutr. 61: 161-168.

Cerretani, L., A. Bendinin, M. T. Rodriguez-Estrada, E. Vittadini and E. Chiavaro. 2009. Microwave heating of different commercial categories of olive oil: Part I. Effect on chemical oxidative stability indices and phenolic compounds. Food Chem. 115: 1381-1388.

Codex Alimentarius Commission. 1999. Codex Standards for Named Vegetable Oils. Codex Alimentarius Commission, CX-STAN 210-1999.

Danneskiold-Samsøe, N. B., D. Andersen, I. D. Radulescu, A. Normann- Hansen, A. Brejnrod, M. Kragh, T. Madsen, C. Nielsen, K. Josefsen, X. Fretté, E. Fjære, L. Madsen, L. I. Hellgren, S. Brix and K. Kristiansen. 2017. A safflower oil-based high fat/high-sucrose diet modulates the gut microbiota and liver phospholipid profiles associated with early glucose intolerance in the absence of tissue inflammation. Mol. Nutr. Food Res. 61(5): 16000528.

Elmadfa, I. and M. Kornsteiner. 2009. Dietary fat intake-a global perspective. Ann. Nutr. Metab. 54(1): 8-14.

FAOSTAT. 2019. Statistical Database of the Food and Agriculture Organization (FAO) of the United Nations. Available from: http:// www.fao.org/faostat/en/\#data/QC. [Last accessed on 2019 Apr 11].

Farahmandfar, R., M. Asnaashari and R. Sayyad. 2015. Comparison antioxidant activity of Tarom Mahali rice bran extracted from different extraction methods and its effect on canola stabilization. J. Food Sci. Techn. 52(10): 6385-6394.
Farhoosh, R., M. H. H. Khodaparast and A. Sharif. 2009. Bene hull oil as a highly stable and antioxidative vegetable oil. Eur. J. Lipid Sci. Technol. 111: 1259-1265.

Fatemi, S. H. and E. G. Hammond. 1980. Analysis of oleate, linoleate and linolenate hydroperoxides in oxidized ester mixtures. Lipids. 15: 379-385.

Franke, S., K. Fröhlich, S. Werner, V. Böhm and F. Schöne. 2010. Analysis of carotenoids and Vitamin E in selected oilseeds, press cakes and oils. Eur. J. Lipid Sci. Technol. 112: 1122-1129.

Fukumoto, L. R. and G. Mazza. 2000. Assessing antioxidant and prooxidant activities of phenolic compounds. J. Agri. Food Chem. 48: 3597-3604.

IUPAC. 1987. Standard Methods for the Analysis of Oils, Fats and Derivatives. $7^{\text {th }}$ ed. Blackwell Jevent Publishers, Oxford, UK.

Irving, D. W., M. C. Shannon, V. A. Breda and B. E. Mackey. 1988. Salinity effects on yield and oil quality of high-linoleate and higholeate cultivars of safflower (Carthamus tinctorius L.). J. Agric. Food Chem. 36: 37-42.

Kadirvel, P., D. Ravi, N. Mukta, M. C. L. Montoya-Coronado, S. B. Ghuge, J. Singh, V. Singh, S. K. Shinde, S. N. Deshmukh, P. Yadav and K. S. Varaprasad. 2017. Genetic distinctiveness of safflower cultivars of India and Mexico as revealed by SSR markers. Plant Genet. Res. 15(6): 474-487.

Lavelli, V. 2002. Comparison of the antioxidant activities of extra virgin olive oils. J. Agric. Food Chem. 50: 7704-7708.

Lee, Y. C., S. W. Oh, J. Chang and I. H. Kim. 2004. Chemical composition and oxidative stability of safflower oil prepared from safflower seed roasted with different temperatures. Food Chem. 84: 1-6.

López-Carrillo, L., M. López-Cervantes, M. H. Ward, J. Bravo-Alvarado and A. Ramírez-Espitia. 1999. Nutrient intake and gastric cancer in Mexico. Int. J. Cancer. 83: 601-605.

Louw, L. 2012. Effects of conjugated linoleic acid and high oleic acid safflower oil in the treatment of children with HPV-induced laryngeal papillomatosis: A randomized, double-blinded and crossover preliminary study. Lipids Health Dis. 11: 136-147.

Maru, R. 2014. Safflower Oil Emulsion as Dietary Supplement and Preparation Thereof. US Patent, No. 8,623,433 B1 issued January 6.

Montoya-Coronado, M. C. L. 2008. Mexican safflower varieties with high tolerance to Ramularia carthami. In: S. E. Knights and T. D. Potter (Eds.), Safflower: Unexploited Potential and World Adaptability. Proceedings of the $7^{\text {th }}$ International Safflower Conference, Wagga Wagga, NSW, Australia.

Moumen, A. B., F. Mansouri, G. Richard, M. Abid, M-L. Fauconnier, M. Sindic, A. El Amrani and H. S. Caid. 2015. Biochemical characterization of the seed oils of four safflower (Carthamus tinctorius) varieties grown in north-eastern of Morocco. Int. J. Food Sci. Technol. 50: 804-810.

Moyano, M. J., A. J. Meléndez-Martínez, J. Alba and F. J. Heredia. 2008. A comprehensive study on the color of virgin olive oils and its relationship with their chlorophylls and carotenoids indexes (II): CIELUV and CIELAB uniform color spaces. Food Res. Int. 41: 513-521.

Ninfali, P., M. Bacchiocca, E. Biagiotti, M. Servili and G. Montedoro. 2002. Validation of the oxygen radical absorbance capacity (ORAC) parameter as a new index of quality and stability of virgin olive oil. J. Am. Oil Chem. Soc. 79(10): 977-982.

Norris, L. E., A. L. Collene, M. L. Asp, J. C. Hsu, L. F. Liu, J. R. Richardson, D. Li, D. Bell, K. Ssei, R. D. Jackson and M. A. Belury. 2009. Comparison of dietary conjugated linoleic acid with safflower oil on body composition in obese postmenopausal 
women with Type 2 diabetes mellitus. Am. J. Clin. Nutr. 90(3): 468-476.

Nurmi, K., V. Ossipov, E. Haukioja and K. Pihlaja. 1996. Variation of total phenolic content and individual low-molecular-weight phenolics in foliage of mountain birch trees (Betula pubescens ssp. tortuosa). J. Chem. Ecol. 22: 2023-2040.

Oomah, B. D., C. Blanchard and P. Balasubramanian. 2008. Phytic acid, phytase, minerals, and antioxidant activity in Canadian dry bean (Phaseolus vulgaris L.) cultivars. J. Agric. Food Chem. 56: 11312-11319.

Oomah, B. D., S. Ladet, D. V. Godfrey, J. Liang and B. Girard. 2000. Characteristics of raspberry (Rubus idaeus L.) seed oil. Food Chem. 69: 187-193.

Owen, R. W., W. Mier, A. Giacosa, W. E. Hull, B. Spiegelhalder and H. Bartsch. 2000. Phenolic compounds and squalene in olive oils: The concentration and antioxidant potential of total phenols, simple phenols, secoiridoids, lignans and squalene. Food Chem. Toxicol. 38(8): 647-659.

Prescha, A., M. Grajzer, M. Dedyk and H. Grajeta. 2014. The antioxidant activity and oxidative stability of cold-pressed oils. J. Am. Oil Chem. Soc. 91(8): 1291-1301.

Prior, R. L., H. Hoang, L. Gu, X. Wu, M. Bacchiocca, L. Howard and R. Jacob. 2003. Assays for hydrophilic and lipophilic antioxidant capacity (oxygen radical absorbance capacity (ORACFL)) of plasma and other biological and food samples. J. Agric. Food Chem. 51: 3273-3279.

Rampure, N. H., A. D. Choudhary, S. J. Jambhulkar and R. S. Badere. 2015. Ethyl methanesulphonate-induced high oleic acid mutants in safflower (Carthamus tinctorius L.). J. Crop Improv. 29(6): 720-727.

Rudel, L. L., J. S. Parks and J. K. Sawyer. 1995. Compared with dietary monounsaturated and saturated fat, polyunsaturated fat protects
African green monkeys from coronary artery atherosclerosis Arterioscler. Thromb. Vasc. Biol. 15(12): 2101-2110.

Sadoudi, R., A. Ammouche and D. Ali Ahmed. 2014. Thermal oxidative alteration of sunflower oil. Afr. J. Food Sci. 8(3): 116-121.

Salaberría, F., D. Constenla, A. A. Carelli and M. E. Carrín. 2016. Chemical composition and physical properties of high oleic safflower oils (Carthamus tinctorius, Var. CW88-OL and CW99OL). J. Am. Oil Chem. Soc. 93: 1383-1391.

Samaniego-Sánchez, C., A. M. Troncoso-González, M. C. García-Parrilla, J. J. Quesada-Granados, H. López-García de la Serrana and M. C. López-Martínez. 2007. Different radical scavenging tests in virgin olive oil and their relation to the total phenol content. Anal. Chim. Acta. 593: 103-107.

Sampieri, C. L. and M. Mora. 2014. Gastric cancer research in Mexico: A public health priority. World J. Gastroenterol. 20(16): 4491-4502.

Senkal, B. C., M. Kiralan and M. F. Ramadan. 2016. Impact of harvest times on the quality characteristics of oils recovered from different safflower (Carthamus tinctorius) cultivars sown in spring and autumn. Eur. Food Res. Technol. 242(3): 371-381.

Shukla, V. K. S. and E. G. Perkins. 1998. Rancidity in encapsulated health-food oils. Int. News Fats Oils Rel. Mat. 9(10): 955-961.

Smith, J. R. 1996. Safflower. $1^{\text {st }}$ ed. AOCS Press, Champaign, IL, USA, pp. 624.

Ulbricht, T. L. V. and D. A. T. Southgate. 1991. Coronary heart disease: Seven dietary factors. Lancet. 338(8773): 985-992.

Weisker, A. C. and G. C. Musa. 2013. Ramularia Leaf Spot Resistant Safflower. US Patent, No. 8,476,486 B2, issued July 2.

Zhang, H. L., A. Nagatsu, T. Watanabe, J. Sakakibara and H. Okuyama. 1997. Antioxidant compounds isolated from safflower (Carthamus tinctorius L.) oil cake. Chem. Pharm. Bull. 45(12): 1910-1914. 